\title{
Insulin-like growth factor-binding protein-1 in the prediction and development of type 2 diabetes in middle-aged Swedish men
}

\author{
M. S. Lewitt • A. Hilding • C.-G. Östenson • S. Efendic • \\ K. Brismar $\cdot$ K. Hall
}

Received: 15 January 2008 / Accepted: 28 March 2008 / Published online: 22 May 2008

(C) Springer-Verlag 2008

\begin{abstract}
Aims/hypothesis Insulin-like growth factor-binding protein1 (IGFBP-1) production in the liver is inhibited by insulin, and low circulating levels are associated with the metabolic syndrome. The aim of this study was to evaluate the predictive role and change in IGFBP-1 concentrations during development of abnormal glucose regulation.

Methods IGFBP-1 levels were determined at baseline and at 10 years in an incident case-control prospective study of Swedish white men aged 35-56 years. Individuals with normal glucose tolerance at baseline who developed abnormal glucose tolerance during a 10 year period $(n=355)$ according to WHO criteria were pair-matched to controls for age and family history of diabetes.

Results Fasting IGFBP-1 concentrations were lower in individuals who later developed abnormal glucose regulation and correlated inversely with fasting proinsulin values $(r=-0.48 ; p<0.0001)$, and both were significant predictors. Individuals in the highest quartile at baseline for an algorithm incorporating fasting IGFBP-1, blood glucose, proinsulin and waist and height had a 40fold increased risk of developing type 2 diabetes compared with the lowest quartile (95\% CI 7.7-214). IGFBP-1 increased $32 \%$ (95\% CI $17-49 \%$ ) during the
\end{abstract}

Electronic supplementary material The online version of this article (doi:10.1007/s00125-008-1016-x) contains supplementary material, which is available to authorised users.

M. S. Lewitt $(\bowtie) \cdot$ A. Hilding $\cdot$ C.-G. Östenson · S. Efendic $\cdot$

K. Brismar $\cdot \mathrm{K}$. Hall

The Rolf Luft Research Center for Diabetes and Endocrinology,

Department of Molecular Medicine and Surgery,

Karolinska Institutet, L1:01,

Karolinska University Hospital,

Stockholm, SE-171 76, Sweden

e-mail: Moira.Lewitt@ki.se
10 years in those developing diabetes and was increased in relation to insulin levels, suggesting the emergence of hepatic insulin resistance. Moreover, elevated IGFBP-1 levels at follow-up were associated with higher $2 \mathrm{~h}$ glucose values during an OGTT.

Conclusions/interpretation Low IGFBP-1 predicts the development of abnormal glucose regulation and, as an inhibitor of the insulin-like actions of insulin-like growth factors, elevated levels of IGFBP-1 after the development of diabetes may also play a pathophysiological role.

Keywords Diabetes prediction - Hepatic insulin resistance Impaired fasting glucose $\cdot$ Impaired glucose tolerance · Insulin-like growth factor-binding protein-1 . Insulin-like growth factor-I - Type 2 diabetes

Abbreviations
$\begin{array}{ll}\text { FHD } & \text { family history of diabetes } \\ \text { IFG } & \text { impaired fasting glucose } \\ \text { IGF-I } & \text { insulin-like growth factor-I } \\ \text { IGFBP-1 } & \text { insulin-like growth factor-binding protein-1 } \\ \text { IGT } & \text { impaired glucose tolerance } \\ \mathrm{Wa}^{2} \mathrm{HtR} & \text { waist }^{2} \text { :height ratio }\end{array}$

\section{Introduction}

Insulin-like growth factor-binding protein-1 (IGFBP-1) is secreted by the liver and has an inhibitory effect on the actions of insulin-like growth factor (IGF)-I and IGF-II in peripheral tissues. IGFBP-1 synthesis is regulated by insulin and other factors that are altered in conditions associated with abnormal glucose regulation. The suppression of IGFBP-1 production by insulin 
is achieved within the physiological range of insulin concentrations [1-3]. There are multiple stimulators, including glucagon [4] and inflammatory cytokines [5, 6]. The pattern of regulation and its inhibitory effect on the insulin-like activity of the IGFs, suggest that IGFBP-1 has a role as a glucose counter-regulator [7]. Adding to the complexity of IGFBP-1 regulation, IGFBP-1 passage across the endothelium is reported to be enhanced by insulin [8], and we have recently discovered a specific IGFBP-1 protease activity [9].

In cross-sectional studies, low circulating concentrations of IGFBP-1 are associated with the metabolic syndrome and cardiovascular disease [10-14]. In a prospective population study, individuals with low IGFBP-1 had increased risk of cardiovascular disease mortality [15]. Surprisingly, few studies have considered its value as a predictive marker of abnormal glucose tolerance. Low IGFBP-1 concentrations in early pregnancy predict the development of gestational diabetes [16]. In one population study individuals with low fasting IGFBP-1 levels were found to have an inverse relationship between IGF-I concentrations and the later development of glucose intolerance [17].

Identification of individuals at high risk of developing type 2 diabetes mellitus should be given high priority in prevention of the disease. In addition to patients with diabetes, individuals with impaired glucose tolerance (IGT) are also at increased risk of micro- and macrovascular disease and premature cardiovascular death [18, 19]. We have recently shown that family history of diabetes (FHD) is associated with increased prevalence of abnormal glucose tolerance [20] especially in men [21]. The aim of the present study was to determine IGFBP-1 levels in this population, in order to evaluate their predictive role and change in concentrations during the development of abnormal glucose regulation.

\section{Methods}

Study population The present study was an incident casecontrol study of Swedish white men who were part of a 10 year follow-up epidemiological survey, the Stockholm Diabetes Prevention Program (SDPP), which is described elsewhere [20-22]. The SDPP is a population-based study of individuals aged 35-56 years who were without known diabetes at the time of recruitment in 1992-1994. To study the impact of diabetes heredity a sample of individuals without FHD were matched to those with FHD by age and municipality. FHD was defined as known diabetes in at least one first-degree relative or at least two second-degree relatives and with an onset of diabetes at an age predominantly above 35 years.

In the baseline study group a normal OGTT was found in 1,422 men with and 1,413 without FHD (Fig. 1). After 10 years, 2,746 men not having type 2 diabetes at baseline were invited to participate in a follow-up study and 2,383 accepted (87\%). The baseline and follow-up studies consisted of a questionnaire covering lifestyle factors, a health examination and an OGTT. The data on FHD were updated at the follow-up and the frequency increased from $51.8 \%$ to $56.7 \%$. Measurements of weight, height and waist were performed with the individuals wearing light indoor clothes and no shoes. Waist was measured in the standing position midway between the lower costal margin and the iliac crest. BP was taken in the supine position. On each occasion a $75 \mathrm{~g}$ OGTT was performed after an

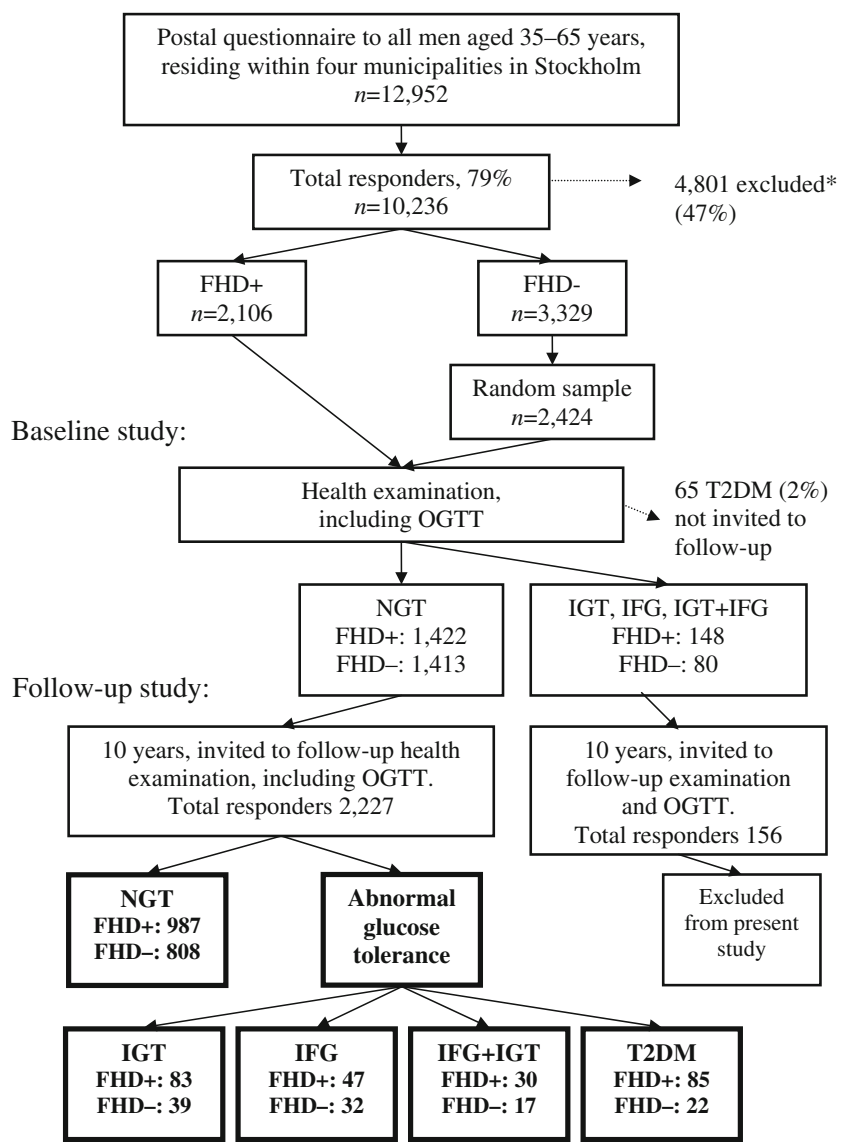

Fig. 1 Study design: selection and follow-up of men in the Stockholm Diabetes Prevention Program. The groups from which the present study population was derived were categorised according to 1999 WHO criteria and are shown in bold type. FHD+, family history of diabetes; FHD-, no family history of diabetes; T2DM, type 2 diabetes mellitus. *Exclusion criteria: already known diabetes $(2.5 \%)$, unclear FHD (27.4\%), insufficient FHD, according to inclusion criteria $(15.0 \%)$, foreign origin $(2.1 \%)$ 
overnight fast. Blood was sampled before and $2 \mathrm{~h}$ after glucose ingestion.

Only those in whom heredity was certain at followup were included in the selection group $(n=2,150)$. The study group comprised 355 individuals who had normal glucose tolerance at baseline and abnormal glucose regulation at follow up. FHD was present in $69 \%$. The controls were pair-matched to cases by random selection of 355 individuals from the group of 1,795 with normal glucose tolerance at baseline and at follow-up, within FHD and age. We did not match for weight or waist measurements in order to determine the effect of these variables. There were 43 men in whom a diagnosis of diabetes mellitus was made during the 10 year period. The diagnosis was made by a physician according to WHO criteria. In those diagnosed before 1999 the 1985 WHO criteria were used and from 1999 the revised criteria were used [23]. Only three in this group had an OGTT in the follow-up study. There were 23 taking oral hypoglycaemic agents, and two on insulin therapy. All other individuals were categorised after OGTT at followup according to 1999 WHO criteria. Individuals with a $2 \mathrm{~h}$ plasma glucose of $7.8-11.0 \mathrm{mmol} / \mathrm{l}$ and fasting values of $<6.1 \mathrm{mmol} / 1$ were classified as having IGT, while impaired fasting glucose (IFG) was defined as fasting glucose levels of $6.1-6.9 \mathrm{mmol} / \mathrm{l}$ and a $2 \mathrm{~h}$ glucose $<7.8 \mathrm{mmol} / \mathrm{l}$. Those with a fasting value of $6.1-6.9 \mathrm{mmol} /$ 1 and a $2 \mathrm{~h}$ glucose of $7.8-11.0 \mathrm{mmol} / 1$ were classified as having combined glucose intolerance (IFG+IGT). There were 64 individuals with a fasting glucose of $\geq 7.0 \mathrm{mmol} /$ $1 \mathrm{and} /$ or $2 \mathrm{~h}$ glucose of $\geq 11.1 \mathrm{mmol} / 1$ who were classified as having diabetes mellitus. In this group 30 had isolated post-challenge hyperglycaemia: 19 individuals had fasting glucose values of $\leq 6.0 \mathrm{mmol} / 1$ and 11 had fasting glucose levels of $6.1-6.9 \mathrm{mmol} / \mathrm{l}$. The group of 11 individuals had similar baseline characteristics to the rest of the type 2 diabetes group and are included in that group for the analyses.

All participants gave informed consent and the study was approved by the Ethics Committee of Karolinska University Hospital and carried out in accordance with the Declaration of Helsinki.

Assays Serum IGFBP-1 was measured by an in-house RIA using a polyclonal antibody and human IGFBP-1 as standard, as previously described [24]. The intra- and inter-assay CV values were $3 \%$ and $10 \%$, respectively. Samples taken from the two OGTT studies 10 years apart from the same individual were analysed in the same assay. IGFBP-1 is stable in samples stored for prolonged periods. When samples were re-analysed after 6 years of storage at $-20^{\circ} \mathrm{C}$, the regression line was $y=-4.61+$ $1.011 x(n=20)$, where $x$ was the original measurement in recently obtained samples and $y$ the value measured after prolonged storage. Phosphorylated and non-phosphorylated IGFBP-1 have similar potencies in this assay (data not shown).

IGF-I was measured in serum by RIA after acid-ethanol extraction and cryoprecipitation, using des(1-3)IGF-I as tracer to minimise interference by IGFBPs [25]. Samples from the same individual were measured in the same assay. The intra- and inter-assay CV values were $4 \%$ and $11 \%$, respectively.

Venous serum glucose was assayed using the glucose oxidase method with a Yellow Spring Glucose Analyzer (Yellow Springs, Yellow Springs, OH, USA). Immunoreactive insulin was assayed by an in-house RIA, using a polyclonal antibody and human insulin as a standard, as previously described [26]. Proinsulin cross-reacts in this assay $100 \%$. Baseline insulin values were measured in assays performed in 1992-1994, and the follow-up measurements were made in 2002-2004. Proinsulin was determined in baseline samples using an ELISA as previously described [22]. The limit of detection was $0.25 \mathrm{pmol} / \mathrm{l}$ and the interassay $\mathrm{CV}$ was $7.6-5.3 \%$ at $1.1-8.0 \mathrm{pmol} / \mathrm{l}$. In addition to intact proinsulin, the four proinsulin intermediates crossreact with $65-99 \%$ efficiency in this assay.

Data analysis The results presented in the tables and figures are means $\pm 95 \%$ CIs. Waist was dependent on height in both the cases $(r=0.23 ; p<0.0001)$ and the controls $(r=0.21 ; p<0.0001)$. Waist ${ }^{2}$ :height ratio $\left(\mathrm{Wa}^{2} \mathrm{HtR}\right)$ ([waist measurement in $\mathrm{cm} / 10]^{2} /[$ height in $\mathrm{m} \times 10]$ ) was used because it abolished the effect of height $(r=0.01$ for both cases and controls) and allowed comparisons between groups. Correction for height has been used when evaluating the impact of waist measurement in other population studies [27]. Wa ${ }^{2} \mathrm{HtR}$, serum IGFBP-1, insulin and proinsulin values were not normally distributed and were log transformed before analysis. Differences between IGFBP-1 at baseline and follow-up were analysed by paired Student's $t$ tests. Since the insulin assays were performed 10 years apart, differences between these time-points were not analysed. Comparison of continuous variables between two or more independent groups was assessed by an unpaired $t$ test or ANOVA.

Linear regression analysis was used to examine the relationship between IGFBP-1 and other variables, and to investigate differences between regression lines analysis of covariance was used. Conditional logistic regression was performed to calculate ORs and 95\% CIs. Variables were categorised in quartiles according to their distribution in the whole group, amongst cases 
Table 1 Baseline data for the control group $(n=355)$

\begin{tabular}{lc}
\hline Variables at baseline & Mean $(95 \% \mathrm{CI})$ \\
\hline Age $($ years $)$ & $47.4(46.9-47.9)$ \\
Height $(\mathrm{m})$ & $1.80(1.79-1.80)$ \\
Weight $(\mathrm{kg})$ & $83.0(81.9-84.2)$ \\
BMI $\left(\mathrm{kg} / \mathrm{m}^{2}\right)$ & $25.7(25.4-26.1)$ \\
Waist $(\mathrm{cm})$ & $92(91-92)$ \\
Wa $^{2} \mathrm{HtR}^{\mathrm{a}}$ & $4.64(4.57-4.72)$ \\
$\mathrm{IGF}_{\mathrm{I}}(\mu \mathrm{gg} / \mathrm{l})^{\mathrm{a}}$ & $182(177-187)$ \\
Systolic BP $(\mathrm{mmHg})$ & $123(122-125)$ \\
Diastolic BP $(\mathrm{mmHg})$ & $79(78-80)$ \\
Glucose $(\mathrm{mmol} / \mathrm{l})$ & \\
$0 \mathrm{~h}$ & $4.6(4.6-4.7)$ \\
$2 \mathrm{~h}$ & $4.4(4.3-4.5)$ \\
Proinsulin $(\mathrm{pmol} / \mathrm{l})^{\mathrm{a}}$ & $6.2(5.8-6.6)$ \\
Insulin $(\mathrm{pmol} / \mathrm{l})^{\mathrm{a}}$ & \\
$0 \mathrm{~h}$ & $102(102-108)$ \\
$2 \mathrm{~h}$ & $270(252-282)$ \\
$\mathrm{IGFBP}-1(\mu \mathrm{g} / \mathrm{l})^{\mathrm{a}}$ & \\
$0 \mathrm{~h}$ & $20(19-21)$ \\
$2 \mathrm{~h}$ & $9(9-10)$ \\
$2 \mathrm{~h} / 0 \mathrm{~h}(\%)$ & $47(46-49)$ \\
\hline
\end{tabular}

${ }^{\mathrm{a}}$ Geometric mean

and their respective controls. The lowest quartile (for glucose, BMI, $\mathrm{Wa}^{2} \mathrm{HtR}$, insulin, proinsulin and algorithms [see below]) or the highest quartile (for IGFBP-1) were used as the reference in the calculation of OR. Algorithms were derived in order to evaluate the combined contribution of variables in a way that could be useful to other investigators in the field. The equations were as follows:

Algorithm 1: f-Glucose $-0.33 \times\left[{ }^{2} \log (\mathrm{f}-\mathrm{IGFBP}-1)\right]$

Algorithm 2: f-Glucose $+\mathrm{Wa}^{2} \mathrm{HtR}$

Algorithm 3: f-Glucose -0.33

$$
\times\left[^{2} \log (\mathrm{f}-\text { IGFBP-1/f-Proinsulin })\right]
$$

Algorithm 4: f-Glucose +0.33

$$
\times\left[{ }^{2} \log \left(\mathrm{Wa}^{2} \mathrm{HtR}\right)-{ }^{2} \log (\text { f-IGFBP-1/f-Proinsulin })\right]
$$

where $\mathrm{f}$ indicates fasting.

Statistical analyses were performed using SAS, version 9.1 (SAS Institute, Cary, NC, USA) and Statistica StatSoft, version 7 (Tulsa, OK, USA). Statistical significance was set at $<0.01$, to take into account the repeated comparisons.

\section{Results}

Baseline values Baseline data for the whole control group are shown in Table 1, for the IGT, IFG and IFG+IGT groups in Table 2 and for the diabetes groups in Table 3. In the diabetes group diagnosed at follow-up 19 men had a normal fasting glucose (mean $5.2 \mathrm{mmol} / 1,95 \%$ CI 4.9-5.4) but met the diagnostic criteria for diabetes $2 \mathrm{~h}$ after a glucose load. This group, shown separately in Table 3, was shorter in stature but otherwise not different from matched controls. They were leaner than the rest of the diabetes group, at both baseline and follow-up (data not shown). In the main diabetes groups $(n=88)$ anthropomorphic measures, glucose, insulin and proinsulin concentrations were markedly different compared with controls matched for heredity and age. In addition both systolic and diastolic BPs were higher than controls. This diabetes group included individuals diagnosed during the 10 years before follow-up evaluation $(n=43)$ as well as those in whom the diagnosis was made for the first time at the follow-up $(n=45)$. These groups did not differ at baseline in the parameters shown in Table 3. The IGT individuals also had higher systolic and diastolic BPs at baseline compared with controls. This was not seen in those with IFG or the IFG+IGT group.

At baseline, IGFBP-1 concentrations fasting and $2 \mathrm{~h}$ after the OGTT, were lower in each of the study groups compared with matched controls (Tables 2 and 3). A notable exception is the subgroup of 19 individuals with isolated post-challenge hyperglycaemia. This group did not have lower IGFBP-1 concentrations at baseline. The suppression in IGFBP-1 after an oral glucose load was similar in all groups and not significantly different from matched controls. IGF-I values were not significantly different from controls in any of the groups. The group with diabetes had a higher percentage of individuals with heredity for diabetes (84\% compared with $65 \%$ for the IGT, IFG and IFG+IGT groups). The pattern in the baseline parameters was similar in those with and without FHD.

In the whole control group, log-transformed fasting IGFBP-1 correlated inversely with log-transformed fasting insulin levels $(r=-0.34 ; p<0.001)$ and with log-transformed proinsulin levels $(r=-0.47 ; p<0.001)$ as well as $\mathrm{Wa}^{2} \mathrm{HtR}$ $(r=-0.40 ; p<0.001)$, BMI $(r=-0.44 ; p<0.001)$ and glucose $(r=-0.19 ; p<0.001)$, which all correlated positively to each other (data not shown). Proinsulin levels alone explained $22 \%$ of the IGFBP-1 variation, while insulin accounted for only $11 \%$. In multiple regression analyses, $26 \%$ of the IGFBP-1 variation could be explained by the variables proinsulin and $\mathrm{Wa}^{2} \mathrm{HtR}(p<0.001)$. Wa ${ }^{2} \mathrm{HtR}$ correlated with age ( $r=0.16 ; p=0.003)$, while IGFBP-1, proinsulin, insulin, BMI and glucose were independent of age. IGF-I showed the expected correlation with age $(r=-0.19 ; p<0.001)$.

Factors predicting the development of abnormal glucose regulation Baseline variables and algorithms were categorised into quartiles and ORs for the development of IGT, 
Table 2 Baseline data for the group having IGT, IFG or IFG+IGT at 10 year follow-up

\begin{tabular}{|c|c|c|c|c|c|c|}
\hline \multirow[t]{2}{*}{ Variables at baseline } & \multicolumn{2}{|l|}{ IGT $(n=122)$} & \multicolumn{2}{|l|}{ IFG $(n=79)$} & \multicolumn{2}{|l|}{ IFG+IGT $(n=47)$} \\
\hline & Mean $(95 \%$ CI) & $p$ value $^{\mathrm{a}}$ & Mean $(95 \% \mathrm{CI})$ & $p$ value $^{\mathrm{a}}$ & Mean $(95 \% \mathrm{CI})$ & $p$ value $^{\mathrm{a}}$ \\
\hline Age (years) & $47.6(46.7-48.4)$ & 0.978 & $46.9(45.9-47.9)$ & 0.901 & $47.3(45.8-48.9)$ & 0.938 \\
\hline Height (m) & $1.79(1.78-1.80)$ & 0.374 & $1.78(1.76-1.80)$ & 0.081 & $1.79(1.77-1.81)$ & 0.362 \\
\hline Weight (kg) & $87.3(85.0-89.6)$ & 0.089 & $85.1(82.7-87.6)$ & 0.135 & $91.1(87.2-95.1)$ & $<0.001$ \\
\hline BMI $\left(\mathrm{kg} / \mathrm{m}^{2}\right)$ & $27.3(26.7-28.0)$ & 0.020 & $26.7(26.1-27.3)$ & 0.002 & $28.3(27.3-29.4)$ & $<0.001$ \\
\hline Waist $(\mathrm{cm})$ & $95(94-97)$ & 0.042 & $93(92-95)$ & 0.083 & $97(95-100)$ & $<0.001$ \\
\hline $\mathrm{Wa}^{2} \mathrm{HtR}^{\mathrm{b}}$ & $5.02(4.87-5.18)$ & 0.022 & $4.86(4.70-5.02)$ & 0.022 & $5.27(5.03-5.53)$ & $<0.001$ \\
\hline IGF-I $(\mu \mathrm{g} / 1)^{\mathrm{b}}$ & $189(181-197)$ & 0.675 & $178(168-189)$ & 0.405 & $188(173-203)$ & 0.504 \\
\hline Systolic BP (mmHg) & $130(127-133)$ & $<0.001$ & $124(122-127)$ & 0.375 & $131(127-135)$ & 0.123 \\
\hline Diastolic BP (mmHg) & $83(81-84)$ & 0.007 & $81(79-82)$ & 0.494 & $84(81-87)$ & 0.067 \\
\hline \multicolumn{7}{|l|}{ Glucose $(\mathrm{mmol} / \mathrm{l})$} \\
\hline $0 \mathrm{~h}$ & $4.7(4.6-4.8)$ & 0.462 & $5.1(4.9-5.2)$ & $<0.001$ & $4.9(4.8-5.1)$ & 0.002 \\
\hline $2 \mathrm{~h}$ & $5.3(5.1-5.5)$ & $<0.001$ & $4.8(4.5-5.1)$ & 0.014 & $5.1(4.8-5.5)$ & $<0.001$ \\
\hline Proinsulin $(\mathrm{pmol} / \mathrm{l})^{\mathrm{b}}$ & $8.2(7.3-9.3)$ & 0.001 & $8.5(7.3-10.0)$ & 0.002 & $9.1(7.5-11.1)$ & $<0.001$ \\
\hline \multicolumn{7}{|l|}{ Insulin $(\mathrm{pmol} / 1)^{\mathrm{b}}$} \\
\hline $0 \mathrm{~h}$ & $120(114-132)$ & 0.067 & $120(108-126)$ & 0.025 & $126(114-138)$ & 0.011 \\
\hline $2 \mathrm{~h}$ & $426(384-474)$ & $<0.001$ & $294(258-330)$ & 0.281 & $378(312-462)$ & $<0.001$ \\
\hline \multicolumn{7}{|l|}{ IGFBP-1 $(\mu \mathrm{g} / 1)^{\mathrm{b}}$} \\
\hline $0 \mathrm{~h}$ & $14(13-16)$ & 0.002 & $16(14-19)$ & 0.027 & $13(10-16)$ & 0.001 \\
\hline $2 \mathrm{~h}$ & $6(6-7)$ & $<0.001$ & $7(6-8)$ & 0.031 & $6(5-7)$ & $<0.001$ \\
\hline $2 \mathrm{~h} / 0 \mathrm{~h}(\%)$ & $45(42-48)$ & 0.148 & $45(41-49)$ & 0.990 & $45(39-50)$ & 0.112 \\
\hline FHD frequency & $68 \%$ & & $59 \%$ & & $64 \%$ & \\
\hline
\end{tabular}

${ }^{\text {a }} p$ value (unpaired $t$ test), cases vs matched controls

${ }^{\mathrm{b}}$ Geometric mean

Table 3 Baseline data for the group having type 2 diabetes at 10 year follow-up

\begin{tabular}{|c|c|c|c|c|c|}
\hline \multirow[t]{3}{*}{ Variables at baseline } & \multicolumn{5}{|c|}{ Type 2 diabetes with fasting glucose at follow-up } \\
\hline & \multicolumn{2}{|c|}{$>6.0 \mathrm{mmol} / 1(n=88)$} & \multicolumn{3}{|c|}{$\leq 6.0 \mathrm{mmol} / \mathrm{l}(n=19)$} \\
\hline & Mean $(95 \% \mathrm{CI})$ & $\begin{array}{l}p \text { value vs } \\
\text { matched controls }\end{array}$ & Mean $(95 \% \mathrm{CI})$ & $\begin{array}{l}p \text { value vs } \\
\text { matched controls }\end{array}$ & $\begin{array}{l}p \text { value vs }>6.0 \mathrm{mmol} / 1 \\
\text { glucose }\end{array}$ \\
\hline Age (years) & $47.4(46.4-48.4)$ & 0.962 & $48.9(47.0-50.9)$ & 0.847 & 0.196 \\
\hline Height (m) & $1.79(1.78-1.80)$ & 0.347 & $1.76(1.73-1.79)$ & 0.009 & 0.077 \\
\hline Weight $(\mathrm{kg})$ & $90.3(87.4-93.1)$ & $<0.001$ & $77.9(73.3-82.5)$ & 0.053 & $<0.001$ \\
\hline $\operatorname{BMI}\left(\mathrm{kg} / \mathrm{m}^{2}\right)$ & $28.2(27.4-29.0)$ & $<0.001$ & $25.1(23.8-26.4)$ & 0.392 & $<0.001$ \\
\hline Waist (cm) & $97(95-99)$ & $<0.001$ & $91(88-93)$ & 0.388 & 0.005 \\
\hline $\mathrm{Wa}^{2} \mathrm{HtR}^{\mathrm{a}}$ & $5.21(5.01-5.43)$ & $<0.001$ & $4.64(4.34-4.95)$ & 0.739 & 0.012 \\
\hline IGF-I $(\mu \mathrm{g} / 1)^{\mathrm{a}}$ & $187(178-197)$ & 0.052 & $173(152-197)$ & 0.821 & 0.306 \\
\hline Systolic BP (mmHg) & $131(128-134)$ & $<0.001$ & $125(118-132)$ & 0.660 & 0.137 \\
\hline Diastolic BP (mmHg) & $83(81-85)$ & $<0.001$ & $79(75-83)$ & 1.000 & 0.116 \\
\hline \multicolumn{6}{|l|}{ Glucose (mmol/1) } \\
\hline $0 \mathrm{~h}$ & $5.1(5.0-5.2)$ & $<0.001$ & $4.6(4.3-5.0)$ & 0.854 & 0.002 \\
\hline $2 \mathrm{~h}$ & $5.6(5.3-5.9)$ & $<0.001$ & $5.7(5.0-6.4)$ & 0.016 & 0.713 \\
\hline Proinsulin $(\mathrm{pmol} / \mathrm{l})^{\mathrm{a}}$ & $12.1(10.5-13.9)$ & $<0.001$ & $5.6(4.2-7.5)$ & 0.708 & $<0.001$ \\
\hline \multicolumn{6}{|l|}{ Insulin $(\mathrm{pmol} / 1)^{\mathrm{a}}$} \\
\hline $0 \mathrm{~h}$ & $138(126-150)$ & $<0.001$ & $114(96-138)$ & 0.374 & 0.157 \\
\hline $2 \mathrm{~h}$ & $402(342-474)$ & $<0.001$ & $354(294-426)$ & 0.415 & 0.132 \\
\hline \multicolumn{6}{|l|}{ IGFBP-1 $(\mu \mathrm{g} / 1)^{\mathrm{a}}$} \\
\hline $0 \mathrm{~h}$ & $14(12-16)$ & $<0.001$ & $20(15-27)$ & 0.774 & 0.036 \\
\hline $2 \mathrm{~h}$ & $6(5-7)$ & $<0.001$ & $9(6-13)$ & 0.803 & 0.071 \\
\hline $2 \mathrm{~h} / 0 \mathrm{~h}(\%)$ & $46(43-50)$ & 0.874 & $44(38-52)$ & 0.248 & 0.584 \\
\hline FHD frequency & $84 \%$ & & $58 \%$ & & \\
\hline
\end{tabular}

${ }^{\mathrm{a}}$ Geometric mean 
IFG or IFG+IGT and diabetes were determined. (Fig. 2; Electronic supplementary material [ESM] Tables 1, 2 and 3). The 19 cases with diabetes with isolated post-challenge hyperglycaemia and fasting glucose $\leq 6.0 \mathrm{mmol} / 1$ were excluded for this analysis. IGF-I was not a significant predictor of abnormal glucose regulation (data not shown). Individuals in the highest quartile for fasting glucose had a five- to tenfold increased risk of developing IFG and type 2 diabetes. When the inverse of IGFBP-1 was used alone, or combined with glucose (Algorithm 1), individuals in the highest quartile had a greater than a tenfold risk of diabetes. There was a trend to an increased prediction if proinsulin was added to IGFBP-1 (Algorithm 3). A similar prediction was obtained for glucose and $\mathrm{Wa}^{2} \mathrm{HtR}$ (Algorithm 2), with those in the highest quartile having a 26 -fold increased risk of diabetes. When all of the variables were combined (Algorithm 4), individuals in the highest quartile at baseline had a 40 -fold increase risk of developing type 2 diabetes compared with the lowest quartile.

When using fasting IGFBP-1 as a continuous variable, the risk of abnormal glucose regulation was increased twofold by each halving of IGFBP-1 (Table 4). In order to evaluate which variables contributed independently in each of the algorithms, models were used where the variables were included separately and as continuous values in the conditional logistic regression analyses (Table 4). When used in Algorithm 1, fasting IGFBP-1 was independently associated with the development of abnormal glucose regulation. When fasting IGFBP-1 and fasting proinsulin were combined (Algorithms 3 and 4) proinsulin was excluded from independent association with the development of IFG or IFG+IGT, and IGFBP-1 was excluded from independent association with the development of diabetes.

Changes in IGFBP-1 at follow-up Overall there was no change in fasting IGFBP-1 concentrations in any of the control groups at 10 year follow-up, compared with baseline (paired $t$ tests). In the individuals who had IGT and/or IFG at the 10 year follow-up, the fasting IGFBP-1 concentrations were unchanged and remained lower than matched controls (Fig. 3a). A similar pattern was seen for each group (IFG, IGT, IFG+IGT) when analysed separately. There was no significant change in fasting IGFBP-1 values in the 19 individuals with diabetes diagnosed on the basis of glucose values $2 \mathrm{~h}$ after oral glucose $(20 \mu \mathrm{g} / 1$ [95\% CI 15-27] and $20 \mu \mathrm{g} / 1$ [95\% CI 13-32] at baseline and follow up, respectively). In those who developed diabetes, fasting IGFBP-1 concentrations were higher at the 10 years followup compared with baseline (paired $t$ tests; Fig. $3 \mathrm{~b}$ ) so that they were not different from their control group at followup. During the OGTT performed at follow-up there was a
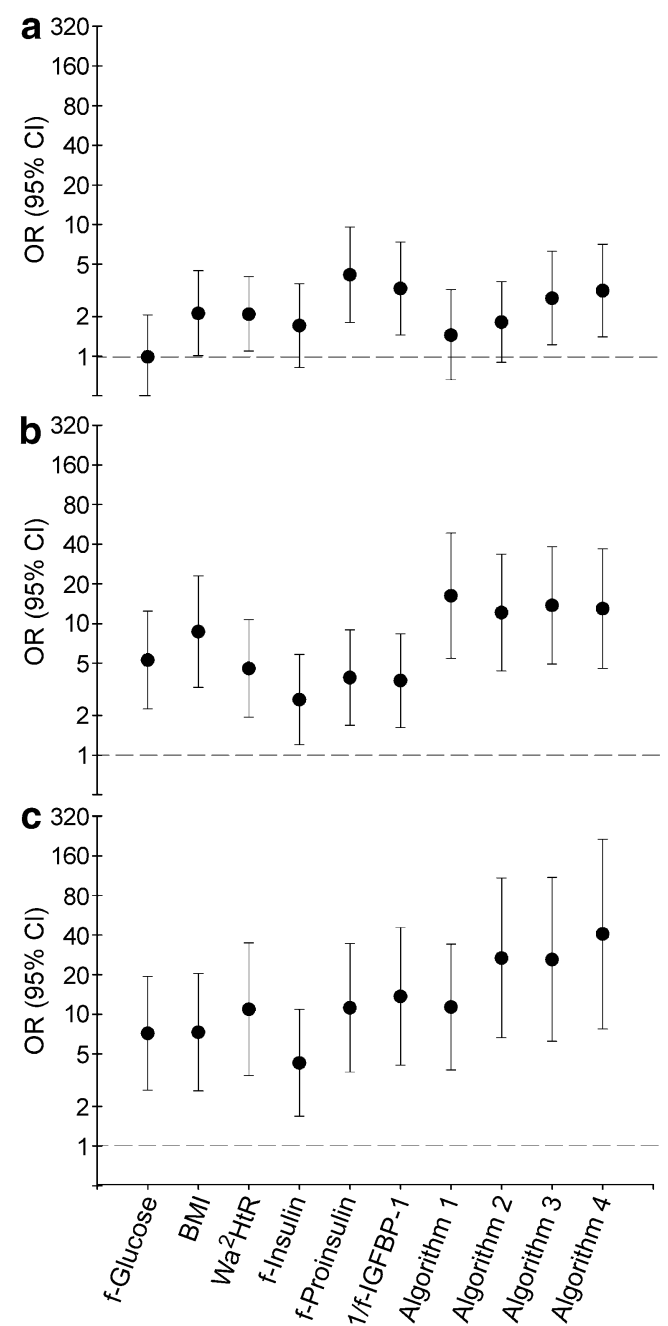

Fig. 2 ORs $(95 \%$ CIs) of variables and algorithms for the development of IGT (a), IFG or IFG+IGT (b) and type 2 diabetes (c). The lowest quartile was used as the reference in the calculation. Note that the inverse of IGFBP-1 was used. f, fasting

similar suppression of IGFBP-1 to about $45 \%$ in all groups (data not shown).

In the group developing diabetes there was a parallel upwards shift of the regression line of fasting IGFBP-1 on fasting insulin at follow-up, which was not seen at baseline. Shown in Fig. 4a, the regression line at 10 year follow-up for the diabetes group was $37 \%$ higher $(F=16.09 ; p<0.001)$ than that of the controls. In the control group, the change in IGFBP-1 was inversely correlated with a change in waist measurement (Fig. 4b). This relationship was not seen in the group developing diabetes with fasting glucose $>6 \mathrm{mmol} / \mathrm{l}$, but was preserved in the 19 with fasting glucose $\leq 6.0 \mathrm{mmol} / 1$.

In the whole diabetes group, the percentage change in IGFBP-1 during 10 years was inversely correlated to the fall in IGF-I during 10 years (Fig. 5a) and to the IGF-I levels at follow-up $(r=-0.32 ; p<0.001)$. There was no significant relationship between the change in IGFBP-1 and IGF-I in the 
Table 4 ORs for the association of baseline variables used in the four algorithms with the development of IGT, IFG or IFG+IGT, and type 2 diabetes at 10 year follow-up: conditional logistic regression analysis is used with variables in continuous values

\begin{tabular}{|c|c|c|c|c|c|c|}
\hline \multirow[t]{2}{*}{ Included variables } & \multicolumn{2}{|l|}{ IGT $(n=122)$} & \multicolumn{2}{|c|}{ IFG or IFG+IGT $(n=126)$} & \multicolumn{2}{|c|}{ Diabetes with fasting glucose $>6.0 \mathrm{mmol} / \mathrm{l}(n=88)$} \\
\hline & OR $(95 \% \mathrm{CI})$ & $p$ value & OR $(95 \% \mathrm{CI})$ & $p$ value & OR $(95 \% \mathrm{CI})$ & $p$ value \\
\hline Fasting IGFBP-1 $1^{\mathrm{a}, \mathrm{b}}$ & $1.70(1.23-2.35)$ & 0.001 & $1.79(1.31-2.46)$ & $<0.001$ & $1.97(1.37-2.82)$ & $<0.001$ \\
\hline \multicolumn{7}{|l|}{ Algorithm 1} \\
\hline Fasting glucose & $1.13(0.67-1.88)$ & 0.654 & $4.61(2.41-8.82)$ & $<0.001$ & $3.56(1.69-7.48)$ & $<0.001$ \\
\hline Fasting IGFBP-1 ${ }^{\mathrm{a}, \mathrm{b}}$ & $1.69(1.22-2.35)$ & 0.002 & $1.76(1.24-2.48)$ & 0.002 & $1.70(1.15-2.51)$ & 0.007 \\
\hline \multicolumn{7}{|l|}{ Algorithm 2} \\
\hline Fasting glucose & $1.07(0.67-1.74)$ & 0.797 & $4.67(2.43-8.97)$ & $<0.001$ & $4.44(1.97-10.01)$ & $<0.001$ \\
\hline $\mathrm{Wa}^{2} \mathrm{HtR}$ & $1.31(0.99-1.72)$ & 0.058 & $2.40(1.48-3.88)$ & $<0.001$ & $2.39(1.50-3.80)$ & $<0.001$ \\
\hline \multicolumn{7}{|l|}{ Algorithm 3} \\
\hline Fasting glucose & $1.10(0.65-1.86)$ & 0.732 & $4.14(2.14-8.02)$ & $<0.001$ & $3.75(1.60-8.79)$ & 0.002 \\
\hline Fasting IGFBP-1 $1^{\mathrm{a}, \mathrm{b}}$ & $1.50(1.06-2.13)$ & 0.022 & $1.58(1.08-2.31)$ & 0.019 & $1.06(0.66-1.72)$ & 0.814 \\
\hline Fasting proinsulin ${ }^{\mathrm{a}}$ & $1.44(1.02-2.04)$ & 0.037 & $1.27(0.87-1.85)$ & 0.212 & $2.33(1.37-3.96)$ & 0.002 \\
\hline \multicolumn{7}{|l|}{ Algorithm 4} \\
\hline Fasting glucose & $1.12(0.65-1.94)$ & 0.675 & $4.72(2.34-9.53)$ & $<0.001$ & 4.06 (1.69-9.77) & 0.002 \\
\hline Fasting IGFBP-1 $1^{\mathrm{a}, \mathrm{b}}$ & $1.56(1.06-2.29$ & 0.024 & $1.55(1.04-2.31)$ & 0.033 & $0.91(0.54-1.53)$ & 0.720 \\
\hline Fasting proinsulin ${ }^{\mathrm{a}}$ & $1.49(1.03-2.15)$ & 0.035 & $0.99(0.64-1.52)$ & 0.963 & $1.96(1.11-3.46)$ & 0.020 \\
\hline $\mathrm{Wa}^{2} \mathrm{HtR}^{\mathrm{a}}$ & $0.76(0.22-2.62)$ & 0.658 & $11.25(1.76-71.87)$ & 0.011 & $5.35(0.70-40.70)$ & 0.105 \\
\hline
\end{tabular}

${ }^{2} \log$-transformed values

${ }^{\mathrm{b}}$ Decreasing values

matched control group. The percentage change in IGFBP-1 also correlated with the $2 \mathrm{~h}$ glucose value (Fig. $5 \mathrm{~b}$ ), and with the percentage glucose response during OGTT in the diabetes group $(r=0.32 ; p=0.009)$, but not with the fasting glucose level. There was no significant correlation with blood glucose values in the matched control group. In addition, fasting IGFBP-1 at follow-up correlated with the $2 \mathrm{~h}$ glucose response during OGTT in the whole diabetes group $(r=0.37 ; p=0.002)$ and not in the controls. There was no relationship between IGFBP-1 levels at baseline and the glucose response at follow-up (data not shown).
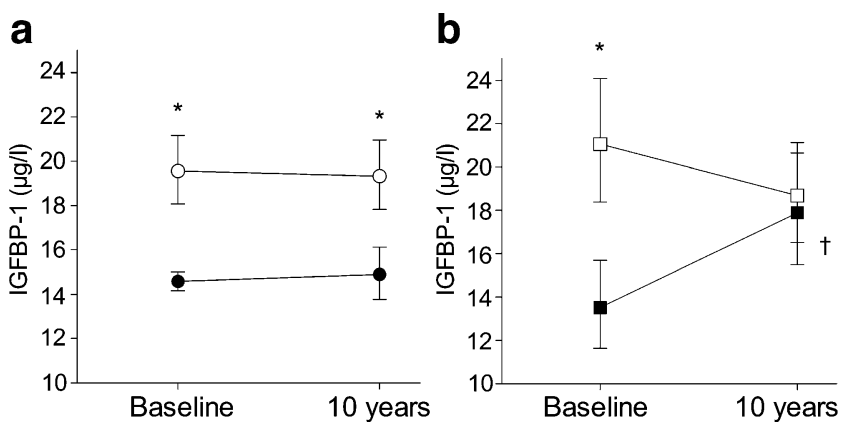

Fig. 3 Fasting IGFBP-1 concentrations at baseline and at the 10 year follow-up in men (black symbols) developing IGT and/or IFG $(\mathbf{a} ; n=$ 248 ) and diabetes $(\mathbf{b} ; n=88)$, compared with their matched control group (white symbols). Values are the geometric means and $95 \%$ CIs. ${ }^{*} p<0.001$ compared with controls (unpaired $t$ test); ${ }^{\dagger} p<0.001$ compared with baseline (paired $t$ test). The 19 diabetic individuals with fasting glucose $\leq 6 \mathrm{mmol} / 1$ and isolated post-challenge hyperglycaemia were excluded

\section{Discussion}

In this case-control study of men enrolled in a populationbased prospective programme, low fasting IGFBP-1 concentrations predicted the development of abnormal glucose regulation 10 years later. When IGFBP-1 was used in combination with glucose, waist, height and proinsulin, individuals in the highest quartile were observed to have a 40-fold increased risk of developing diabetes compared with the lowest quartile. In individuals developing diabetes mellitus during a 10 year interval, fasting IGFBP-1 concentrations increased to levels greater than expected for the fasting insulin concentration and change in waist measurement. The higher fasting IGFBP-1 levels in this group of individuals with type 2 diabetes were inversely related to the change in IGF-I levels and correlated positively with glucose values $2 \mathrm{~h}$ after an oral glucose challenge.

As a result of the study design, a majority of the individuals in this case-control study have a family history of type 2 diabetes. The original cohort was selected so that $50 \%$ had FHD, a group in which there was a twofold higher prevalence of disturbed glucose metabolism [20]. Thus, even though the control group was matched for age and heredity, these observations are in a population of men with high genetic and social heredity for diabetes and further studies in more representative populations, including women, are required before the results can be extrapolated. Apart from age and heredity we have not determined whether the predictive value of IGFBP-1 is independent of other known 


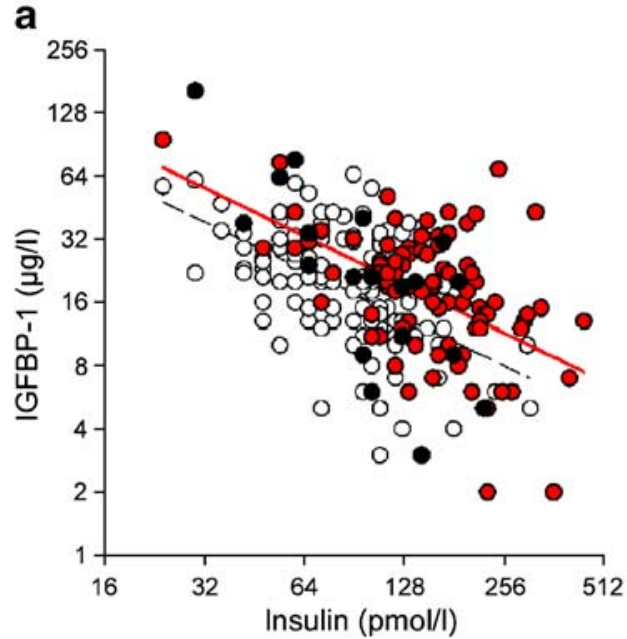

Fig. 4 Relationship between fasting IGFBP-1 and insulin concentrations (a) and the change in IGFBP-1 and change in waist (b) in men developing type 2 diabetes at 10 year follow-up. The individuals developing diabetes $(n=107)$ are represented by the red and black circles and solid regression lines and are compared with their matched control group (white symbols, dotted regression lines). The 19 individuals with fasting glucose $\leq 6 \mathrm{mmol} / \mathrm{l}$ and isolated post-challenge

risk factors, such as high triacylglycerol levels. This will also need to be evaluated in future studies.

Fasting glucose levels predicted both diabetes and IFG in this population. Other long-term studies that are more representative of the general population also suggest that fasting blood glucose values below the WHO criteria for IFG strongly predict type 2 diabetes [28-30]. In a study in western Finland in a population enriched for FHD, fasting glucose $\geq 5.6 \mathrm{mmol} / 1$ and $\mathrm{BMI} \geq 30 \mathrm{~kg} / \mathrm{m}^{2}$ predicted diabetes 6 years later (HR 3.7 [31]). We suggest that a com-

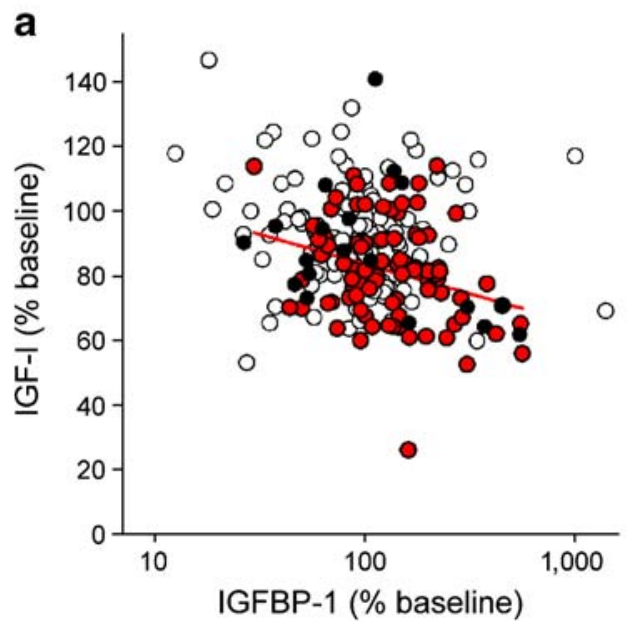

Fig. 5 In individuals developing type 2 diabetes, the change in IGFBP-1 concentrations at 10 year follow-up is related to the fall in IGF-I levels (a, $n=107)$ and the $2 \mathrm{~h}$ glucose value in those diagnosed by OGTT $(\mathbf{b}, n=64)$. The individuals are represented by the red and black circles and solid regression lines and are compared with their

\section{b}

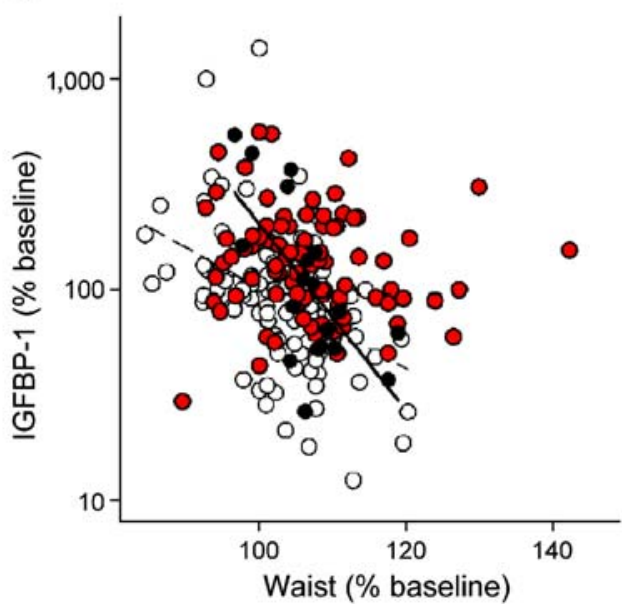

hyperglycaemia are identified by the black circles and regression line. a Regression lines: controls: ${ }^{2} \log ($ IGFBP-1 $)=9.099-\left[0.758 \times{ }^{2} \log \right.$ (insulin)]; diabetes: ${ }^{2} \log ($ IGFBP-1 $)=9.657-\left[0.765 \times{ }^{2} \log (\right.$ insulin $\left.)\right]$. b Correlation coefficients: controls: $r=-0.44, p<0.001$; diabetes with fasting glucose $>6 \mathrm{mmol} / \mathrm{l}: r=-0.12, p=0.289$; diabetes fasting glucose $\leq 6.0 \mathrm{mmol} / \mathrm{l}: r=0.66, p=0.002$

bination of FHD, high-normal fasting glucose and increased waist measurement (in relation to height) or low fasting IGFBP-1 identifies a group at very high risk.

There are several studies in which IGFBP-1 was shown to be a marker of hyperinsulinaemia $[1,32,33]$. As expected, fasting IGFBP-1 concentrations correlated inversely with fasting insulin levels in our study. However, the relationship of IGFBP-1 with fasting proinsulin, which has low hepatic extraction, was stronger, suggesting that the IGFBP-1 levels reflect portal insulin delivery [34, 35]. Consistent with

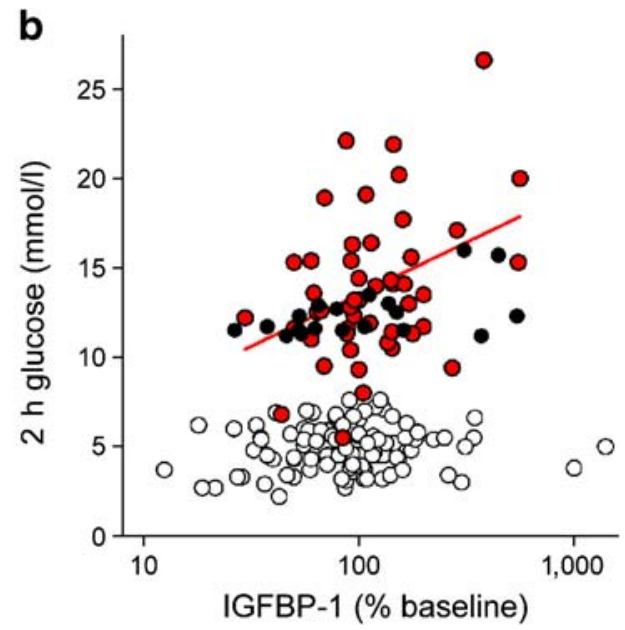

matched control group (white circles). The 19 individuals with fasting glucose $\leq 6 \mathrm{mmol} / 1$ and isolated post-challenge hyperglycaemia are identified by the black symbols. The regression lines on IGFBP-1 ( $\%$ baseline) for the whole diabetes group for IGF-I ( $\%$ baseline) was $r=$ $-0.326, p<0.001$ and the $2 \mathrm{~h}$ glucose value was $r=0.345, p=0.006$ 
proinsulin being a more stable marker of insulin secretion, it has previously been shown that the risk of progression to type 2 diabetes was more strongly related to fasting 32,33 split proinsulin than to the fasting insulin level [36].

Fasting IGFBP-1 concentrations increased after 10 years in those developing diabetes, but not in those developing IFG and/or IGT. One possible explanation for this is that IGFBP-1 is a marker of declining beta cell function, just as has been observed for the incremental insulin response to glucose [31]. This is not supported, however, by our observation that, although the inverse relationship between IGFBP-1 and insulin was maintained after the development of diabetes, the regression line was shifted upwards so that IGFBP-1 levels were relatively increased. This is consistent with the emergence of hepatic insulin resistance, for which we have previously hypothesised that IGFBP-1 can be used as a marker [37]. If this is the case, hepatic insulin resistance, although an important determinant of blood glucose response during OGTT [38], is not the earliest feature in the development of type 2 diabetes. Hepatic insulin resistance is associated with reduced hepatic insulin extraction [39], which may also contribute to the altered relationship with IGFBP-1. If this is the case, IGFBP-1 may be a more reliable marker of hepatic insulin sensitivity than peripheral insulin levels. An upwards shift in the relationship between IGFBP-1 in relation to insulin is seen in other chronic conditions, such as those associated with low IGF-I levels, including growth hormone deficiency [40]. There are many other factors that have an impact on circulating IGFBP-1 and we can only speculate on the role of other counter-regulatory hormones [41] and of inflammatory cytokines [5, 6], which might also have played a role in the relative increase in IGFBP-1 at 10 years in type 2 diabetes. It has been reported that, in patients with low fasting IGFBP-1, low IGF-I concentrations are associated with the development of IGT or type 2 diabetes 4.5 years later [17]. In that report the IGF-I levels showed the expected decline in relation to increasing age, the tertile of individuals with low IGF-I being older than the other groups. This may explain the relationship with IGT or type 2 diabetes since in our age-matched case-control study IGF-I did not play a role as a predictive marker.

Abnormal glucose regulation is clearly a heterogeneous condition and the groups in our study varied in their baseline characteristics. Only the IGT group had higher systolic and diastolic BPs. It is well documented that this group is at significant risk of both large- and small-vascular complications and all-cause mortality, independently of progression to diabetes $[19,42]$. On the other hand, individuals with IFG do not appear to have this degree of risk [42]. The value of low fasting IGFBP-1 concentrations in predicting IGT was of particular interest, since its use in screening may avoid the need for an OGTT in identifying individuals at risk. There was a group of 19 individuals with normal fasting glucose and post-challenge hyperglycaemia meeting the $\mathrm{WHO}$ criteria for diabetes [42]. This group was lean, BP was not increased and, exceptionally amongst the study groups, fasting IGFBP1 levels were not suppressed 10 years before diagnosis. It is not surprising that we identified this patient group, which is the majority in the category 'isolated post-challenge hyperglycaemia', and therefore represents a significant proportion of cases of newly diagnosed diabetes in population studies, and is characterised by leanness and an increased risk of cardiovascular complications and death [18, 43, 44].

Could the association of low IGFBP-1 with the development of abnormal glucose regulation have causal or pathological roles? A potential role of IGFs in the pathogenesis of cardiovascular disease has long been recognised. In cross-sectional studies low serum IGFBP-1 levels are associated with an unfavourable cardiovascular risk profile in diabetes and in populations without diabetes [10, 11, 45, 46]. Low IGF-I is also associated with cardiovascular risk factors [45, 47], independently of low IGFBP-1 [12, 15]. It is clear, however, that the IGFBP-1 levels change during the emergence of the diabetic state, increasing because of either hepatic insulin resistance or the influence of stimulatory factors such as cytokines. This increase may result in change in its pathological role at the tissue level. There is a lot of evidence that the IGF system plays a role in glucose homeostasis [48]. In animal models high IGFBP-1 concentrations are associated with glucose intolerance and insulin resistance [49] and IGFBP-1 administration leads to inhibition of the insulin activity of endogenous IGFs [50]. Indeed our observations of increased glucose values and lower IGF-I levels in relationship to increased levels of IGFBP-1 would support such a role. The factors responsible for the increase in IGFBP-1 in diabetes and its role in catabolism and glucose intolerance will be further investigated in future studies.

Acknowledgements The authors thank I.-L. Wivall-Helleryd, E. Sandberg and Y. Strömberg for their technical assistance in performing IGFBP-1, IGF-I and insulin assays, and the nurses, technicians and other staff members of the healthcare centres and laboratories who carried out the OGTTs and other assays. The study was supported by grants from the Swedish Research Council, Stockholm County Council, the Erling-Persson Family Foundation, the Berth von Kantzows Foundation, the Swedish Council for Working Life and Social Research, the Swedish Diabetes Association, Novo Nordisk Scandinavia and GlaxoSmithKline.

Duality of interest The authors declare that there is no duality of interest associated with this manuscript.

\section{References}

1. Suikkari A-M, Koivisto VA, Koistinen R, Seppälä M, YkiJärvinen H (1989) Dose-response characteristics for suppression of low molecular weight plasma insulin-like growth factorbinding protein by insulin. J Clin Endocrinol Metab 68:135-140 
2. Conover CA, Lee PDK, Kanaley JA, Clarkson JT, Jenson MD (1992) Insulin regulation of insulin-like growth factor binding protein-1 in obese and nonobese humans. J Clin Endocrinol Metab 74:1355-1360

3. Lee PDK, Jensen MD, Divertie GD, Heiling VJ, Katz HH, Conover CA (1993) Insulin-like growth factor-binding protein-1 response to insulin during suppression of endogenous insulin secretion. Metabolism 42:409-414

4. Hilding A, Möller C, Hall KE (2002) Glucagon and GLP-1 stimulate IGFBP-1 secretion in Hep G2 cells without effect on IGFBP-1 mRNA. Growth Horm IGF Res 12:60-68

5. Samstien B, Hoimes ML, Fan J, Frost RA, Gelato MC, Lang CH (1996) IL-6 stimulation of insulin-like growth factor binding protein (IGFBP)-1 production. Biochem Biophys Res Commun 228:611-615

6. Lang CH, Nystrom GJ, Frost RA (1999) Regulation of IGF binding protein-1 in Hep G2 cells by cytokines and reactive oxygen species. Am J Physiol 276:G719-G727

7. Lewitt MS, Baxter RC (1991) Insulin-like growth factor-binding protein-1: a role in glucose counterregulation? Mol Cell Endocrinol 79:C147-C152

8. Bar RS, Boes M, Clemmons DR et al (1990) Insulin differentially alters transcapillary movement of intravascular IGFBP-1, IGFBP-2 and endothelial cell IGF-binding proteins in the rat heart. Endocrinology 127:497-499

9. Wang J, Shafqat J, Hall K et al (2006) Specific cleavage of insulin-like growth factor-binding protein-1 by a novel protease activity. Cell Mol Life Sci 63:2405-2414

10. Heald AH, Cruickshank JK, Riste LK et al (2001) Close relation of fasting insulin-like growth factor binding protein-1 (IGFBP-1) with glucose tolerance and cardiovascular risk in two populations. Diabetologia 44:333-339

11. Heald AH, Siddals KW, Fraser W et al (2002) Low circulating levels of insulin-like growth factor binding protein-1 (IGFBP-1) are closely associated with the presence of macrovascular disease and hypertension in type 2 diabetes. Diabetes 51:2629-2636

12. Heald AH, Anderson SG, Ivison F, Laing I, Gibson JM, Cruickshank K (2003) C-reactive protein and the insulin-like growth factor (IGF)-system in relation to risk of cardiovascular disease in different ethnic groups. Atherosclerosis 170:79-86

13. Kalme T, Seppala M, Qiao Q et al (2005) Sex hormone-binding globulin and insulin-like growth factor-binding protein-1 as indicators of metabolic syndrome, cardiovascular risk, and mortality in elderly men. J Clin Endocrinol Metab 90:1550-1556

14. Rajpathak SN, McGinn AP, Strickler HD et al (2008) Insulin-like growth factor-(IGF)-axis, inflammation, and glucose intolerance among older adults. Growth Horm IGF Res 18:166-173

15. Laughlin GA, Barrett-Connor E, Criqui MH, Kritz-Silverstein D (2004) The prospective association of serum insulin-like growth factor I (IGF-I) and IGF-binding protein-1 levels with all cause and cardiovascular disease mortality in older adults: the Rancho Bernardo Study. J Clin Endocrinol Metab 89:114-120

16. Qiu C, Vadachkoria S, Meryman L, Frederick IO, Williams MA (2005) Maternal plasma concentrations of IGF-1, IGFBP-1, and C-peptide in early pregnancy and subsequent risk of gestational diabetes mellitus. Am J Obstet Gynecol 193:1691-1697

17. Sandhu MS, Heald AH, Gibson JM, Cruickshank JK, Dunger DB, Wareham NJ (2002) Circulating concentrations of insulin-like growth factor-I and development of glucose intolerance: a prospective observational study. Lancet 359:1740-1745

18. Barrett-Connor E, Ferrara A (1998) Isolated postchallenge hyperglycemia and the risk of fatal cardiovascular disease in older women and men. The Rancho Bernardo Study. Diabetes Care 21:1236-1239
19. Singleton JR, Smith AG, Russell JW, Feldman EL (2003) Microvascular complications of impaired glucose tolerance. Diabetes 52:2867-2873

20. Kuhl J, Hilding A, Ostenson CG, Grill V, Efendic S, Bavenholm P (2005) Characterisation of subjects with early abnormalities of glucose tolerance in the Stockholm Diabetes Prevention Programme: the impact of sex and type 2 diabetes heredity. Diabetologia 48:35-40

21. Hilding A, Eriksson AK, Agardh EE et al (2006) The impact of family history of diabetes and lifestyle factors on abnormal glucose regulation in middle-aged Swedish men and women. Diabetologia 49:2589-2598

22. Grill V, Dinesen B, Carlsson S, Efendic S, Pedersen O, Ostenson CG (2002) Hyperproinsulinemia and proinsulin-to-insulin ratios in Swedish middle-aged men: association with glycemia and insulin resistance but not with family history of diabetes. Am J Epidemiol 155:834-841

23. World Health Organization (1999) Definition, diagnosis and classification of diabetes mellitus and its complications: report of a WHO consultation. Part 1. Diagnosis and classification of diabetes mellitus. WHO, Geneva

24. Póvoa G, Roovete A, Hall K (1984) Cross-reaction of serum somatomedin-binding protein in a radioimmunoassay developed for somatomedin-binding protein isolated from human amniotic fluid. Acta Endocrinol 107:563-570

25. Bang P, Eriksson U, Sara V, Wivall I-L, Hall K (1991) Comparison of acid ethanol extraction and acid gel filtration prior to IGF-I and IGF-II radioimmunoassays: improvement of determinations in acid ethanol extracts by the use of truncated IGF-I as radioligand. Acta Endocrinol (Copenh) 124:620-629

26. Herbert V, Lau KS, Gottlieb CW, Bleicher SJ (1965) Coated charcoal immunoassay of insulin. J Clin Endocrinol Metab 25:1375-1384

27. Hadaegh F, Zabetian A, Harati H, Azizi F (2006) Waist/height ratio as a better predictor of type 2 diabetes compared to body mass index in Tehranian adult men - a 3.6-year prospective study. Exp Clin Endocrinol Diabetes 114:310-315

28. Ohlson LO, Larsson B, Bjorntorp P et al (1988) Risk factors for type 2 (non-insulin-dependent) diabetes mellitus. Thirteen and one-half years of follow-up of the participants in a study of Swedish men born in 1913. Diabetologia 31:798-805

29. Dinneen S, Maldonado D, Leibson C et al (1998) Effects of changing diagnostic criteria on the risk of developing diabetes. Diabetes Care 21:1408-1413

30. Bjørnholt JV, Erikssen G, Liestølt K, Jervell J, Erikssen J, Thaulow E (2001) Prediction of type 2 diabetes in healthy middle aged men with special emphasis on glucose homeostasis. Results from 22.5 years' follow-up. Diabet Med 18:261-267

31. Lyssenko V, Almgren P, Anevski D et al (2005) Predictors of and longitudinal changes in insulin sensitivity and secretion preceding onset of type 2 diabetes. Diabetes 54:166-174

32. Mogul HR, Marshall M, Frey M et al (1996) Insulin-like growth factor-binding protein-1 as a marker for hyperinsulinemia in obese menopausal women. J Clin Endocrinol Metab 81:4492-4495

33. Liew CF, Wise SD, Yeo KP, Lee KO (2005) Insulin-like growth factor binding protein-1 is independently affected by ethnicity, insulin sensitivity, and leptin in healthy, glucose-tolerant young men. J Clin Endocrinol Metab 90:1483-1488

34. Mohamed-Ali V, Pinkney JH, Panahloo A, Cwyfan-Hughes S, Holly JM, Yudkin JS (1999) Insulin-like growth factor binding protein-1 in NIDDM: relationship with the insulin resistance syndrome. Clin Endocrinol 50:221-228

35. Kamoda T, Saitoh H, Inudoh M, Miyazaki K, Matsui A (2006) The serum levels of proinsulin and their relationship with IGFBP1 in obese children. Diabetes Obes Metab 8:192-196 
36. Wareham NJ, Byrne CD, Williams R, Day NE, Hales CN (1999) Fasting proinsulin concentrations predict the development of type 2 diabetes. Diabetes Care 22:262-270

37. Lewitt MS, Hall K, Bang P, Brismar K (2005) Altered response of IGFBP-1 to nutritional deprivation in type 2 diabetes mellitus. Metabolism 54:275-280

38. Båvenholm PN, Pigon J, Östensson C-G, Efendic S (2001) Insulin sensitivity of suppression of endogenous glucose production is the single most important determinant of glucose tolerance. Diabetes 50:1449-1454

39. Kotronen A, Vehkavaara S, Seppala-Lindroos A, Bergholm R, Yki-Jarvinen H (2007) Effect of liver fat on insulin clearance. Am J Physiol Endocrinol Metab 293:E1709-E1715

40. Hilding A, Brismar K, Degerblad M, Thorén M, Hall K (1995) Altered relation between circulating levels of insulin-like growth factor-binding protein-1 and insulin in growth hormone-deficient patients and insulin-dependent diabetic patients compared to that in healthy subjects. J Clin Endocrinol Metab 80:2646-2652

41. Hilding A, Brismar K, Thorén M, Hall K (1993) Glucagon stimulates insulin-like growth factor binding protein-1 secretion in healthy subjects, patients with pituitary insufficiency, and patients with insulin-dependent diabetes mellitus. J Clin Endocrinol Metab $77: 1142-1147$

42. DECODE Study Group, on behalf of the European Diabetes Epidemiology Group (2001) Glucose tolerance and cardiovascular mortality: comparison of fasting and 2-hour diagnostic criteria. Arch Intern Med 161:397-405
43. Shaw JE, Hodge AM, de Courten M, Chitson P, Zimmet PZ (1999) Isolated post-challenge hyperglycaemia confirmed as a risk factor for mortality. Diabetologia 42:1050-1054

44. Qiao Q, Tuomilehto J, Borch-Johnsen K (2003) Post-challenge hyperglycaemia is associated with premature death and macrovascular complications. Diabetologia 46(Suppl 1):M17-M21

45. Janssen JAMJL, Stolk RP, Pols H, Grobbee DE, Lamberts SWJ (1998) Serum total IGF-I, free IGF-I, and IGFBP-1 levels in an elderly population-relation to cardiovascular risk factors and disease. Arterioscler Thromb Vasc Biol 18:277-282

46. Harrela M, Koistinen R, Tuomilehto J, Nissinen A, Seppälä M (2000) Low serum insulin-like growth factor-binding protein-1 is associated with an unfavourable cardiovascular risk profile in elderly men. Ann Med 32:424-428

47. Juul A, Scheike T, Davidsen M, Gyllenborg J, Jorgensen T (2002) Low serum insulin-like growth factor I is associated with increased risk of ischemic heart disease: a population-based case-control study. Circulation 106:939-944

48. Brismar K, Lewitt MS (2005) The IGF system in insulin resistance and diabetes mellitus. In: Houston MS, Holly J, Feldman E (eds) Nutrition and the IGF system. Humana, Totowa, NJ, pp 251-270

49. Rajkumar K, Barron D, Lewitt MS, Murphy LJ (1995) Growth retardation and hyperglycemia in insulin-like growth factor binding protein-1 transgenic mice. Endocrinology 136:4029-4034

50. Lewitt MS, Denyer GS, Cooney GJ, Baxter RC (1991) Insulinlike growth factor-binding protein-1 modulates blood glucose levels. Endocrinology 129:2254-2256 